Instituto de Estudos Sócio-Ambientais

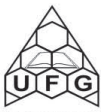

ISSN 0101708X

\title{
BOLETIM GOIANO DE GEOGRAFIA
}

v. 24, n. 1-2, jan./dez. 2004

VI Congresso Brasileiro de Geógrafos

Setenta anos da AGB: as transformações do espaço e a geografia do século XXI
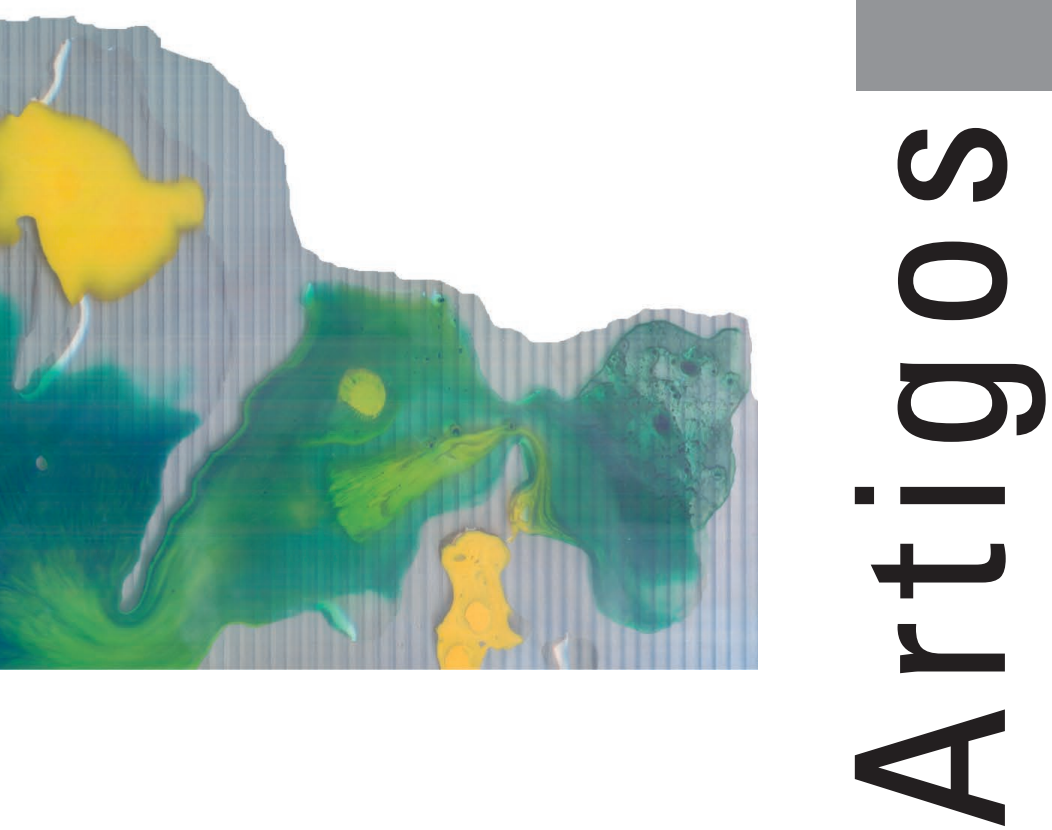


\title{
AVALIAÇÕES DA QUALIDADE DO AR EM PAULÍNIA-SP*
}

\author{
EVALUATIONS OF THE QUALITY OF THE AIR IN PAULÍNIA, SÃO PAULO
}

\author{
Mirian Ramos Gutjahr - IG/SMA/SP \\ gutjahrmr@igeologico.sp.gov.br \\ José Roberto Tarifa - UFMT
}

\section{Resumo}

A obtenção de dados relativos à poluição do ar é sistematicamente difícil. 0 presente trabalho aborda a utilização de dados 'proxi' ou indiretos e sua comparação com dados de monitoramento da qualidade do ar, com o propósito de avaliar a qualidade do ar no município de Paulínia/SP. Levantamentos pontuais de poluição do ar foram realizados pela agência ambiental na Região Metropolitana de São Paulo - RMSP, Cubatão e outros 17 municípios do Estado, que tem sido alvo de maior atenção quanto à qualidade ambiental. Os parâmetros físico-químicos e climáticos monitorados são: partículas inaláveis (PI), dióxido de enxofre $\left(\mathrm{SO}_{2}\right)$, ozônio $\left(\mathrm{O}_{3}\right)$, monóxido de carbono $\left(\mathrm{CO}_{2}\right)$, óxidos de nitrogênio $\left(\mathrm{NO}_{\mathrm{x}}\right)$, umidade relativa $(\%)$, temperatura $\left({ }^{\circ} \mathrm{C}\right)$, velocidade $(\mathrm{m} / \mathrm{s})$ e direção do vento (direção predominante/24hs). Observou-se que as concentrações dos poluentes são diretamente influenciadas pelas condições climáticas atuantes no período. A pesquisa de opinião pública realizada em 2001, comparada com a pesquisa semelhante realizada, entre 1994 e 1995, tiveram o objetivo de traçar um perfil das condições ambientais no município, através das atitudes, hábitos, percepções e expectativas dos seus moradores. Observou-se que um fator de grande incômodo para a maior parte da população é a ocorrência de maus odores e que os mesmos estão ligados ao conceito vigente de poluição do ar.

Palavras-chave: Qualidade do ar, Paulínia-SP.

\begin{abstract}
In Brazil, obtaining data relative to air pollution is systematically difficult. The present work approaches the use of proxy or indirect data, comparing it to data on air quality monitoring with the purpose to evaluate the quality of the air in the county of Paulínia, SP, Brazil. Punctual surveys on air pollution were carried out by an environmental agency in the Greater São Paulo Metropolitan Area, Cubatão, and other 17 counties within the state, which has been a target of increased attention in terms of environmental concerns. The following physiochemical and climatic parameters were monitored: inhaleable particular matter, sulphur dioxide $\left(\mathrm{SO}_{2}\right)$, ozone $\left(\mathrm{O}_{3}\right)$, carbon monoxide $\left(\mathrm{CO}_{2}\right)$, nitrogen oxide $\left(\mathrm{NO}_{\mathrm{x}}\right)$, relative humidity $(\%)$, temperature $\left({ }^{\circ} \mathrm{C}\right)$, and wind speed $(\mathrm{m} / \mathrm{s})$ and direction (predominant direction/24hrs). It was observed that concentrations of pollutants are directly influenced by the climatic conditions active within that period. A 2001 public poll, when compared to a similar one carried out between 1994 and 1995 had the objective of tracing a profile of the environment conditions in the county through the attitudes, habits, perceptions and hopes of its residents. It was observed that, for most of the population, a factor of great discomfort is the occurrence of putrid smells, and that these are connected to the present concept of air pollution.
\end{abstract}

Key-words: Quality of the air, Paulínia-SP. 


\section{Introdução}

$\mathrm{O}$ ar que respiramos é formado por muitos componentes químicos, mas os componentes naturais primários principais são o nitrogênio $\left(\mathrm{N}_{2}\right)$, o oxigênio $\left(\mathrm{O}_{2}\right)$ e o vapor d'água $\left(\mathrm{H}_{2} \mathrm{O}\right)$. Outras substâncias são também encontradas em pequenas quantidades,como o dióxido de carbono, argônio, néon, hélio, hidrogênio e metano.

Embora esses elementos possam ser gerados por fontes naturais, as atividades humanas têm apresentado um efeito prejudicial na composição da atmosfera, introduzindo um sem-número de resíduos químicos tóxicos, como por exemplo, o dióxido de enxofre $\left(\mathrm{SO}_{2}\right)$, o monóxido de carbono (CO), compostos orgânicos voláteis, óxidos de nitrogênio $\left(\mathrm{NO}_{\mathrm{x}}\right)$ e partículas sólidas conhecidas como material particulado. Os poluentes atmosféricos têm um efeito prejudicial sobre a saúde e o bem estar dos seres humanos. Esse efeito se define como uma mudança prejudicial mensurável e observável devido a um poluente atmosférico. Um poluente também pode afetar plantas e animais, como também materiais não-vivos - pinturas, metais, telas, objetos em mármore, arenito etc.

\section{A área de estudo}

O município de Paulínia dista cerca de $130 \mathrm{~km}$ da cidade de São Paulo. Localiza-se na região Centro-Sudeste do Estado de São Paulo, na Depressão Periférica Paulista, em latitude $22^{\circ} 45^{\prime} 47^{\prime \prime}$ sul e longitude 4709'07” oeste. Com área de $154 \mathrm{~km}^{2}$, apresenta 2/3 dessa área (98\%) com ocupação urbana. Paulínia encontra-se em posição privilegiada no que tange aos recursos hidrográficos, com o rio Atibaia, um dos principais formadores do rio Piracicaba, cortando o município em sua área centra na direção leste-oeste. Ainda a norte o rio Jaguari faz divisa municipal com Cosmópolis. O município faz parte da Região Metropolitana de Campinas, região essa que ocupa posição econômica importante nos níveis estadual e nacional. O município abriga a Refinaria do Planalto - REPLAN desde 1972, o que transformou a pacata e pequena Paulínia em pólo industrial, origem de grande crescimento populacional e urbano e também origem das preocupações ambientais, devido às contaminações do solo, do ar e das águas. 


\section{Procedimentos metodológicos}

Para uma melhor compreensão dos estudos e monitoramentos de poluição do ar já realizados no município de Paulínia, foi realizada uma revisão dos estudos pontuais realizados pela agência ambiental Companhia de Tecnologia de Saneamento Ambiental de São Paulo - CETESB, uma vez que esta é a mesma responsável pelo monitoramento e avaliação da qualidade do ar na Região Metropolitana de São Paulo - RMSP, Cubatão e outros 17 municípios no interior. ${ }^{1}$

Devido à escala de problemas quanto à poluição do ar, a RMSP e Cubatão tem recebido maior atenção da empresa. Nos 17 municípios do interior do Estado tem sido monitoradas e avaliadas as concentrações de dióxido de enxofre $-\mathrm{SO}_{2}$ e fumaça. Em Paulínia esses poluentes foram monitorados desde janeiro de 1985, com coletas a cada seis dias a partir de 1987. A tabela 1 descreve os períodos nos quais foram realizados monitoramentos e avaliações da qualidade do ar no município de Paulínia.

Tabela 1: Períodos de monitoramento de poluição do ar em Paulínia.

\begin{tabular}{|c|c|c|c|c|c|c|c|c|c|c|c|c|c|c|}
\hline \multirow{2}{*}{ Ano } & \multicolumn{12}{|c|}{ Meses } & \multirow{2}{*}{$\begin{array}{c}\mathrm{SO}_{2} \mathrm{e} \\
\text { fumaça }\end{array}$} & \multirow{2}{*}{ Local de observação } \\
\hline & $\mathrm{J}$ & $\mathbf{F}$ & M & A & $\mathbf{M}$ & $\mathrm{J}$ & $\mathrm{J}$ & $\mathrm{A}$ & $\mathrm{S}$ & 0 & $\mathbf{N}$ & D & & \\
\hline 1985 & $\mathrm{x}$ & $\mathrm{x}$ & & & & $\mathrm{x}$ & $\mathrm{x}$ & & & & & & & \multirow{7}{*}{ Pça. 28 de Fevereiro } \\
\hline 1986 & & & & & & & & & & & & & $\mathrm{x}$ & \\
\hline 1987 & & & & & & & & & & & & & $\mathrm{x}$ & \\
\hline 1988 & & & & & & & & & & & & & $\mathrm{x}$ & \\
\hline 1989 & $\mathrm{x}$ & $\mathrm{x}$ & $\mathrm{x}$ & & & & & & & & & & $\mathrm{x}$ & \\
\hline 1990 & & & & & & & & & & & & & $\mathrm{x}$ & \\
\hline 1991 & & & & & & & & & & & & & $\mathrm{x}$ & \\
\hline 1992 & $\mathrm{x}$ & $\mathrm{x}$ & $\mathrm{x}$ & & & & & & & & & & $\mathrm{x}$ & \multirow{6}{*}{ R. Oscar Seixas de Queirós ${ }^{(1)}$} \\
\hline 1993 & & & & & & & & & & & & & $\mathrm{x}$ & \\
\hline 1994 & & & & & & & & & & & & & $\mathrm{x}$ & \\
\hline 1995 & & & & & & & & & & & & & $\mathrm{x}$ & \\
\hline 1996 & & & & & & & & & & & & & $\mathrm{x}$ & \\
\hline 1997 & & & & & & & & & & & & & $\mathrm{x}$ & \\
\hline 1998 & & & & & & $\mathrm{x}$ & $\mathrm{x}$ & $\mathrm{x}$ & & & & & & \multirow{2}{*}{$\begin{array}{l}\text { Centro Municipal de Ensino Profissionali- } \\
\text { zante de Paulínia - Av. Brasil - V. Bressane }\end{array}$} \\
\hline 1999 & & & & & & & $\mathrm{x}$ & $\mathrm{x}$ & $\mathrm{x}$ & $\mathrm{x}$ & $\mathrm{x}$ & $\mathrm{x}$ & & \\
\hline 2000 & & & & & & & & $\mathrm{x}$ & $\mathrm{x}$ & $\mathrm{x}$ & $\mathrm{x}$ & $\mathrm{x}$ & & Pça. Ver. O. Pietrobon - V. Bressane ${ }^{(3)}$ \\
\hline
\end{tabular}

(1) PI, $\mathrm{SO}_{2}, \mathrm{NO}_{2}, \mathrm{O}_{3}$.

(2) Estação volante - rede telemétrica - PI, $\mathrm{SO}_{2}, \mathrm{CO}, \mathrm{NO}_{2}, \mathrm{O}_{3}$.

(3) Estação fixa - rede telemétrica - PI, $\mathrm{SO}_{2}, \mathrm{CO}, \mathrm{NO}_{2}, \mathrm{O}_{3}$ - temperatura, umidade relativa, vento - velocidade. e direção. 
Conforme a Tabela 1, no período de janeiro a março de 1992 foram monitorados de hora em hora os seguintes parâmetros: partículas inaláveis (PI), dióxido de enxofre $\left(\mathrm{SO}_{2}\right)$, ozônio $\left(\mathrm{O}_{3}\right)$, monóxido de carbono $\left(\mathrm{CO}_{2}\right)$, óxidos de nitrogênio $\left(\mathrm{NO}_{\mathrm{x}}\right)$, umidade relativa $(\%)$, temperatura $\left({ }^{\circ} \mathrm{C}\right)$, velocidade $(\mathrm{m} / \mathrm{s})$ e direção do vento (direção predominante/24hs). Considerando os poluentes analisados, segundo a empresa, o único elemento que ultrapassou o padrão de qualidade do ar naquela época, foi o ozônio (1 ultrapassagem/ hora), sendo que os demais poluentes atenderam aos padrões fixados (Resolução CONAMA n ${ }^{\circ} 3$ ).

Com base nos dados registrados, a qualidade do ar esteve boa durante $71,4 \%$ do período, regular durante $27,1 \%$ do período e inadequada durante 1,4\% do período. Devendo ser lembrado que há uma variação sazonal da qualidade do ar, e que na região Sudeste o período mais desfavorável para dispersão dos poluentes está compreendido entre os meses de maio a agosto, quando são registrados os maiores índices de poluição. O período de janeiro a março não é representativo do período mais desfavorável do ano. Além desses dados de $\mathrm{SO}_{2}$ e fumaça, a empresa, através de estação móvel, realizou algumas campanhas para a avaliação da qualidade do ar no município. Pelo que se pode apurar, foram realizadas medições em: janeiro e fevereiro, e junho e julho de 1985, janeiro a março de 1989 e janeiro a março de 1992. Durante esse período foram registradas, por duas vezes, a ultrapassagem do padrão de qualidade do ar do poluente ozônio.

Dado ao contínuo crescimento industrial e populacional observado no período, nova avaliação foi efetuada em 1998, quando novo estudo de avaliação da qualidade do ar foi realizado através de medições dos poluentes e parâmetros meteorológicos, no período de junho a agosto. Nesta avaliação, além da análise dos poluentes atmosféricos, foi dado enfoque aos dados de vento (direção e velocidade) e à localização das principais fontes de poluição do ar, com o propósito de identificar a procedência dos problemas de mau odor sentido pelos habitantes do município e de outros no entorno, reclamados à unidade regional da agência ambiental. Fez-se um levantamento de todas a reclamações de odor registradas no período, em Paulínia, Campinas e Barão Geraldo, e comparou-se com as condições do vento (direção e velocidade) associadas.

Constataram-se os seguintes fatos: durante os 56 dias observados no período de 04/06 a 13/08/1998, foram recebidas 71 reclamações de odor de moradores de Paulínia. Desses dias, observou-se: 31 dias com calmarias, 25 dias com vento na hora da reclamação (sendo que desses, $70 \%$ tiveram cal- 
maria nas 3 horas anteriores) e 15 dias sem dados. O maior número de reclamações (41) vieram da Vila Bressani, seguidas dos bairros João Aranha (5), Ouro Negro (5) e Balneário Tropical (6), situadas nas porções sul e oeste da cidade respectivamente.

As reclamações provenientes da região central de Paulínia, na maioria das vezes ocorreram com vento fraco $(<1,5 \mathrm{~m} / \mathrm{s})$, o que tornou difícil determinar a fonte responsável pelo odor. Mas indicou que sob condições de estagnação atmosférica, ou seja, de fraca dispersão de poluentes pelo vento, o município sofre influência do odor dos gases emitidos pelas indústrias localizadas nas áreas circunvizinhas.

Nos três dias em que a velocidade do vento foi mais significativa ( $>$ $2,0 \mathrm{~m} / \mathrm{s}$ ), a identificação da origem pelo reclamante pareceu bastante procedente. Sob condições de vento de SE, a reclamação cita a empresa Galvani como responsável, o que parece ser bem possível devido a sua localização. Nos demais casos, sob condições de ventos do quadrante Norte, as reclamações citam a Rhodia e a Replan. Nos bairros mais afastados do centro, a situação é semelhante à área central, a maioria das reclamações ocorreram sob condições de ventos fracos.

Embora a agência ambiental, via de regra, desloque-se até o local da reclamação, nem sempre é constatado o problema, visto haver normalmente um lapso de tempo, de duas horas em média, entre a chamada e o atendimento. Durante esse período pode ter ocorrido a redução da emissão ou uma alteração nas condições de transporte atmosférico.

Com relação às reclamações recebidas de moradores de Campinas, constataram-se os seguintes fatos: das 62 reclamações recebidas, 34 foram de Barão Geraldo e 17 da Cidade Universitária - UNICAMP, bairros de Campinas próximos a Paulínia. Foi recebida também uma reclamação da cidade de Sumaré.

Em um dia, 17/06/98, a empresa recebeu 28 reclamações desde as 7:30 h até as 21:00 h, todas citando a empresa Rhodia como responsável. Observa-se que a Rhodia é citada como responsável em $87,1 \%$ dos casos. Na análise de vento, pode-se observar que, nos dias e horários das reclamações, o vento predominante foi do quadrante N-W, correspondendo à localização da Rhodia em relação àqueles bairros de Campinas. Desse modo, pode-se afirmar que na maioria dos eventos observados no município de Campinas, a Rhodia foi a provável origem de reclamações de odor.

As concentrações dos poluentes são diretamente influenciadas pelas condições atuantes no período. Parâmetros como a altura da inversão térmica, turbulência atmosférica, umidade e outros, além da direção e velocidade 
do vento, são importantes condições locais que determinam os níveis medidos de concentração dos poluentes, além, é claro, da intensidade de emissões realizadas pelas indústrias. Altos níveis de concentração em uma determinada estação de monitoramento, podem ocorrer não só pela condição local desfavorável à dispersão, como pelo transporte de poluentes de regiões vizinhas. Tal fato torna-se evidente especialmente na Região Metropolitana de Campinas, tal é o adensamento urbano e industrial observado.

Foi realizada também pela CETESB, entre 1994 e 1995, uma pesquisa de opinião pública em Paulínia3 com o objetivo de traçar um perfil das condições ambientais no município, através das atitudes, hábitos, percepções, esperanças e opiniões dos seus moradores. Também foram objetivos: avaliar o grau de significância dos problemas ambientais, levantar as principais fontes de emissão de poluição ambiental, entre outros. O procedimento metodológico para a realização da referida pesquisa utilizou as 'Unidades de Área', que veio a ser o mapa da cidade de Paulínia, com a listagem de ruas em ordem alfabética e dividido em quadrados. Foram selecionadas 136 ruas e obteve-se 127 entrevistas com moradores.

Os resultados obtidos pela agência ambiental na ocasião foram os seguintes: a maior parte dos entrevistados era do sexo feminino e $50 \%$ apresentou idades entre 35 e 54 anos. Com relação à escolaridade, verificou-se que $31 \%$ era de analfabetos ou não tinham o curso fundamental completo, e $42 \%$ tinha fundamental completo ou ginasial incompleto. Na avaliação do grau de satisfação em morar no município e motivos, verificou-se que 70\% dos entrevistados apresentou grande satisfação em morar em Paulínia pelo sossego, pela facilidade de serviços, boa vizinhança, segurança etc. Pequena porcentagem (5\%) demonstrou insatisfação em viver na cidade pelos mesmos motivos citados pelos satisfeitos, só que em sentido contrário, e mencionando também poluição ambiental e problemas de saneamento. Com relação a problemas do cotidiano, as maiores preocupações dos moradores referem-se a: poluição do ar (56\%), desemprego, poluição das águas e segurança, seguidos em menores porcentagens de presença de insetos e roedores, ausência de áreas verdes, poluição sonora, água potável, rede de esgotos e coleta de lixo.

De acordo com a Prefeitura de Paulínia, o ‘lixão' da cidade foi transformado em aterro sanitário desde 1993. O esgoto da cidade até 1991 não recebia nenhum tratamento antes de ser jogado in natura no Rio Atibaia altura do bairro Bela Vista, embora a água, captada superficialmente do Rio Jaguari, tratada e fornecida pela SABESP, seja de boa qualidade. 
A maioria das indústrias de Paulínia encontra-se às margens do Rio Atibaia e do Ribeirão Anhumas, assim sendo, ambos recebem os eflúvios industriais após tratamento prévio. O Ribeirão Anhumas recebe também $40 \%$ dos esgotos sem tratamento, coletados no Município de Campinas.O Ribeirão Anhumas é afluente do Rio Atibaia e, tanto o Rio Atibaia quanto o Rio Jaguari, são formadores do Rio Piracicaba. Em 19904, a partir de análises efetuadas pela CETESB, e com base na Resolução CONAMA no 20/86, o Rio Jaguari, no trecho que representa o limite norte do município de Paulínia, e o trecho do Rio Atibaia, anterior à confluência do Ribeirão Anhumas, foram considerados como classe I (DBO” até 3mg/l, OD não inferior a 6 mg/l). O Ribeirão Anhumas e o Rio Atibaia, até atingir a represa de Salto Grande, foram considerados Classe IV (OD superior a $2 \mathrm{mg} / \mathrm{l}$ ), significando qualidade muito ruim da água. Esses cursos d'água, entretanto, são legalmente considerados como Classe II, necessitando urgente reclassificação.

\section{Entrevistas em Paulínia}

Com o propósito de conhecer a opinião da população de Paulínia, quanto: ao conforto ambiental, hábitos e percepções quanto a poluição do ar e da água, ocorrência de doenças cárdio-respiratórias e/ou dermatológicas na família, e satisfação em residir na cidade, foram realizadas 171 entrevistas, nos dias 21 a 24/01/2001. As entrevistas foram informais e as pessoas foram abordadas em suas atividades diárias, nas ruas e praças do Centro e dos seguintes bairros: Centro (Santa Cecília e Nova Paulínia), Vila Bressani, Vila Monte Alegre, Jardim Planalto, João Aranha e Betel. Não foram entrevistadas pessoas em indústrias.

Foram entrevistados 87 mulheres e 84 homens, distribuídos da seguinte forma:

Tabela 2: Idade e ocupação de entrevistados em Paulínia.

\begin{tabular}{|c|c|c|c|c|c|c|c|c|c|}
\hline \multicolumn{5}{|c|}{ Mulheres } & \multicolumn{5}{|c|}{ Homens } \\
\hline Idade $^{*}$ & $\%$ & Ocupação & & $\%$ & Idade $^{*}$ & $\%$ & Ocupação & & $\%$ \\
\hline A- 29 & 33,4 & Estudantes & 11 & 12,7 & A- 7 & 8,3 & Estudantes & 3 & 3,6 \\
\hline B- 51 & 58,6 & Empregadas & 52 & 59,8 & B- 59 & 70,2 & Empregados & 62 & 73,8 \\
\hline \multirow{3}{*}{$\mathrm{C}-7$} & \multirow{3}{*}{8,0} & Desempregadas & 15 & 17,2 & \multirow{3}{*}{ C - 18} & \multirow{3}{*}{21,5} & Desempregados & 6 & 7,1 \\
\hline & & \begin{tabular}{|l|} 
Aposentadas \\
\end{tabular} & 3 & 3,4 & & & \multirow{2}{*}{ Aposentados } & \multirow{2}{*}{13} & \multirow{2}{*}{15,5} \\
\hline & & \begin{tabular}{|l|} 
Donas-de-casa \\
\end{tabular} & 6 & 6,9 & & & & & \\
\hline
\end{tabular}

A - Jovens; B - Adultos; C - Idosos. 
Observou-se que a maior parte dos entrevistados, tanto mulheres $(58,6 \%)$ quanto homens $(70,2 \%)$ encontram-se na faixa etária 'adultos', maior porcentagem de mulheres 'jovens' $(33,4 \%)$ em comparação com os homens $(8,3 \%)$ e maior número de homens 'idosos' (21,5\%) em comparação com as mulheres (8\%). Notou-se ser mais freqüente encontrar homens idosos em praças e jardins, do que mulheres idosas - denotando o costume.

Com relação à ocupação, constatou-se que a maior parte dos entrevistados, tanto mulheres (60\%) quanto homens (74\%) encontravam-se empregados naquele período, contra $17 \%$ e $7 \%$ de desempregados, respectivamente. Todos declararam-se com dificuldades para voltar ao mercado de trabalho. Nenhum dos entrevistados eram trabalhadores das indústrias e uma reclamação constante foi que as indústrias em Paulínia não privilegiam os moradores do município. Um indício dessa reclamação pode ser observado no final do expediente à saída de uma indústria - dos inúmeros ônibus para transporte dos trabalhadores, apenas um indicava "Paulínia"; os demais indicavam "Sumaré", "Americana”, "Cosmópolis", "Campinas" e até mesmo "São Paulo". A maioria dos entrevistados encontrava-se empregada no setor de 'serviços'.

A maior parte dos estudantes, 13\% mulheres e 4\% homens, constituiu-se de jovens do ensino médio. Com relação a aposentados, observou-se baixa incidência de mulheres (3\%) nessa categoria e oriundas do serviço público, contra 15\% de homens. Neste item, observa-se a ocorrência de uma categoria de ocupação ainda exclusiva de mulheres, ou seja - 'donas-decasa', que respondeu por 7\% das entrevistadas.

Tabela 3: Tempo de residência.

\begin{tabular}{|l|c|c|c|c|}
\hline \multicolumn{1}{|c|}{$\begin{array}{c}\text { TEMPO DE RESIDÊNCIA } \\
\text { em Paulínia }\end{array}$} & \multicolumn{2}{c|}{$\begin{array}{c}\text { HOMENS (84) } \\
\text { Freqüência\% }\end{array}$} & \multicolumn{2}{c|}{$\begin{array}{c}\text { MULHERES (87) } \\
\text { Freqüência\% }\end{array}$} \\
\hline De 1 a 5 anos & 15 & 18 & 18 & 20,7 \\
\hline De 6 a 10 anos & 16 & 19 & 7 & 8 \\
\hline De 11 a 15 anos & 7 & 8,4 & 17 & 19,6 \\
\hline De 16 a 20 anos & 9 & 11 & 22 & 25,4 \\
\hline De 21 a 25 anos & 10 & 12 & 9 & 10,4 \\
\hline De 26 a 30 anos & 12 & 14,4 & 11 & 12,6 \\
\hline De 31 a 35 anos & 4 & 4,9 & 1 & 1,1 \\
\hline De 36 a 40 anos & 4 & 4,9 & 1 & 1,1 \\
\hline De 41 a 45 anos & 2 & 2,5 & 1 & 1,1 \\
\hline Acima de 45 anos & 4 & 4,9 & 0 & 0 \\
\hline
\end{tabular}


Com referência ao tempo de residência (Tabela 3), destacaram-se os períodos de 1 a 5 anos e 16 a 20 anos com 18\% cada, seguidos dos períodos de 6 a 10 anos, 11 a 15 anos, 21 a 25 anos e 26 a 30 anos, com porcentagens variando entre 12 e $15 \%$.

Pode-se observar que a grande maioria dos entrevistados - 91\%, ou mudaram-se para Paulínia ou nasceram em Paulínia, após a instalação do pólo industrial no município. Apenas 9\% constituiu-se de antigos moradores da cidade, que foram capazes de comparar e comentar o 'antes e o depois' do evento mencionado. Esse fato entretanto não impediu que os moradores externassem suas dúvidas e reclamações contra condições ambientais, que no seu entender apresentam-se irregulares.

Com base em trabalhos de campo anteriores ao período das entrevistas, observou-se que um fator de grande incômodo para a maior parte da população é a ocorrência de maus odores e que os mesmos estão intimamente ligados ao conceito vigente de poluição do ar. Poluição do ar nem sempre se vê, ao passo que odores podem ser sentidos. Com relação a esse fator, um maior número (73) e porcentagem (84\%) de mulheres mostraram-se mais sensíveis à ocorrência de maus odores, contra 61 - 73\% dos homens, embora esse seja um valor também alto. Algumas mulheres ( $3-3 \%)$, espontaneamente, reclamaram da ocorrência de pó e fumaça, embora tenham indicado que esse fator não seja freqüente. Entre os homens, $15 \%$ não opinaram sobre maus odores, enquanto todas as mulheres opinaram sobre esse problema.

Porcentagem semelhante de mulheres e homens - 13\% e 12\%, indicaram não sentir esse problema.

Tabela 4: Sensibilidade a odores.

\begin{tabular}{|l|c|c|c|c|}
\hline \multirow{2}{*}{\multicolumn{1}{|c|}{ Odores }} & \multicolumn{2}{c|}{ Mulheres } & \multicolumn{2}{c|}{ Homens } \\
\cline { 2 - 5 } & Freqüência & $\%$ & Freqüência & $\%$ \\
\hline Sentem mau odor & 73 & 84 & 61 & 73 \\
\hline Não sentem mau odor & 11 & 13 & 10 & 12 \\
\hline Reclamaram de pó e fumaça & 3 & 3 & - & - \\
\hline Não opinaram & - & - & 13 & 15 \\
\hline
\end{tabular}

Além da ocorrência de odores, os entrevistados foram indagados sobre o período de incidência - diário, semanal e sazonal e sua freqüência e tipos de tempo durante as ocorrências. 
O período diário suscitou respostas imediatas e mais objetivas.

Tabela 5: Ocorrência de maus odores - período do dia.

\begin{tabular}{|l|c|c|c|c|}
\hline \multirow{2}{*}{\multicolumn{1}{|c|}{ Período do dia }} & \multicolumn{2}{c|}{ Mulheres } & \multicolumn{2}{c|}{ Homens } \\
\cline { 2 - 5 } & Fr. & \% & Fr. & \% \\
\hline A qualquer hora & 1 & 1 & 4 & 5 \\
\hline Manhã & 19 & 22 & 17 & 20 \\
\hline Madrugada & 2 & 2 & 4 & 5 \\
\hline Tarde & 17 & 20 & 21 & 25 \\
\hline Crepúsculo & 5 & 6 & 5 & 6 \\
\hline Noite & 29 & 33 & 22 & 26 \\
\hline Não sabem & 14 & 16 & 11 & 13 \\
\hline
\end{tabular}

De acordo com os resultados obtidos, pode-se apreender que os períodos do dia nos quais a ocorrência de maus odores é mais incômoda, tanto para as mulheres como para os homens, são a manhã, a tarde e a noite, totalizando 75\% e 71\% respectivamente. As mulheres apresentaram-se mais susceptíveis a essa ocorrência no período da noite com $33 \%$, contra $26 \%$ dos homens, refletindo talvez o hábito de permanecerem acordadas até 'mais tarde'. Em contrapartida, os homens são mais susceptíveis à ocorrência de maus odores no período da madrugada com 5\%, contra $2 \%$ das mulheres, refletindo o hábito diário de levantar cedo para ir trabalhar. Porcentagem reduzida de manifestação quanto a essa ocorrência refere-se ao período do final da tarde (tardinha) com 6\% para ambos os sexos e 'à qualquer hora' com $1 \%$ e $5 \%$ para mulheres e homens respectivamente. As questões referentes a ‘quando ocorrem' os maus odores foram relacionadas à freqüência em geral (sempre, nunca, às vezes etc.), semanal e sazonal. Essa abordagem prejudicou a análise através de porcentagens, pois os entrevistados puderam responder com mais que uma freqüência, como por exemplo: 'durante a semana' e 'no inverno'.

De qualquer modo, do universo de 87 mulheres e 84 homens, 29 mulheres responderam que os maus odores ocorrem 'sempre' e 15 mulheres disseram que esse problema ocorre 'de vez em quando', ao passo que 28 homens indicaram 'sempre' e 9 homens 'de vez em quando'. Um número menor de mulheres e homens indicaram a freqüência semanal, não indicando uma tendência de opinião sobre a ocorrência de maus odores durante a semana ou nos finais de semana. A grande maioria indicou a ocorrência mais freqüente do problema 'no verão' e um número significativo, 17 mulheres e 16 homens, indicaram 'no inverno'. 
Tabela 6: Ocorrência de maus odores.

\begin{tabular}{|l|c|c|}
\hline \multirow{2}{*}{\multicolumn{1}{|c|}{ Freqüência temporal }} & Mulheres & Homens \\
\cline { 2 - 3 } & Fr. & Fr. \\
\hline Sempre & 29 & 28 \\
\hline De vez em quando & 15 & 9 \\
\hline Durante a semana & 7 & 10 \\
\hline Finais de semana & 10 & 8 \\
\hline Verão & 40 & 40 \\
\hline Inverno & 17 & 16 \\
\hline Não sabe & 3 & - \\
\hline
\end{tabular}

Com relação aos tipos de tempo, durante os quais são observados a ocorrência de maus odores, tanto para mulheres quanto para homens, destacaram-se as condições atmosféricas - os tempos 'chuvoso e frio' e 'quente e seco', os quais são aparentemente contraditórios com relação ao regime de chuvas na região, com verões chuvosos e invernos menos chuvosos. Esses tipos de tempo significaram a opinião de $47 \%$ das mulheres e $55 \%$ dos homens. Com relação aos homens, destacou-se ainda o tipo de tempo 'chuvoso e quente', com $12 \%$. É interessante notar que uma porcentagem considerável de mulheres e homens, não souberam responder sobre sob quais condições atmosféricas ocorrem maus odores, ou simplesmente não responderam sobre o assunto.

Tabela 7: Ocorrência de maus odores - Tipos de tempo.

\begin{tabular}{|l|c|c|c|c|}
\hline \multirow{2}{*}{\multicolumn{1}{|c|}{ Tipos de tempo }} & \multicolumn{2}{c|}{ Mulheres } & \multicolumn{2}{c|}{ Homens } \\
\cline { 2 - 5 } & Fr. & $\%$ & Fr. & $\%$ \\
\hline Chuvoso e frio & 22 & 24 & 26 & 31 \\
\hline Quente e seco & 20 & 23 & 20 & 24 \\
\hline Chuvoso e quente & 5 & 6 & 10 & 12 \\
\hline Frio e seco & 4 & 5 & 6 & 7 \\
\hline Com vento & 1 & 1 & 4 & 5 \\
\hline Sem vento & 1 & 1 & 1 & 1 \\
\hline Depois da chuva & 4 & 5 & - & 0 \\
\hline Qualquer tempo & 4 & 5 & 1 & 1 \\
\hline Não sabe & 12 & 14 & 10 & 12 \\
\hline Não opinaram & 14 & 16 & 6 & 7 \\
\hline
\end{tabular}


Tabela 8: Grau de satisfação.

\begin{tabular}{|l|c|c|c|c|}
\hline \multirow{2}{*}{\multicolumn{1}{|c|}{ Grau de satisfação em residir em Paulínia }} & \multicolumn{2}{c|}{ Mulheres } & \multicolumn{2}{c|}{ Homens } \\
\cline { 2 - 5 } & Fr. & \% & Fr. & \% \\
\hline Muito satisfeita(o)s & 19 & 22 & 24 & 29 \\
\hline Satisfeita(o)s & 51 & 59 & 49 & 58 \\
\hline Insatisfeita(o)s & 11 & 12 & 9 & 11 \\
\hline Não responderam & 6 & 7 & 2 & 2 \\
\hline
\end{tabular}

Tabela 9: Origens de mau odor.

\begin{tabular}{|l|c|c|}
\hline $\begin{array}{c}\text { Origens citadas como causadoras de mau odor, } \\
\text { fumaça, poeira, poluição em Paulínia }\end{array}$ & Mulheres & Homens \\
\hline Indústrias em geral & 9 & 10 \\
\hline Replan & 10 & 26 \\
\hline Rio Atibaia & - & 1 \\
\hline Rio Anhumas & 15 & 16 \\
\hline Brahma & 7 & 1 \\
\hline 'Pólo químico' & 1 & 1 \\
\hline Betel (bairro) & 1 & 2 \\
\hline Purina & 3 & 4 \\
\hline Shell & 3 & 1 \\
\hline Gás & 1 & 3 \\
\hline Nutriplant & 1 & 1 \\
\hline Papelão Bresler & 1 & 3 \\
\hline Pedreira (pó) & 2 & 1 \\
\hline Galvani & - & 13 \\
\hline Zeneca (Syngenta) & 6 & 1 \\
\hline Rhodia & 1 & 2 \\
\hline Du Pont' & 1 & 2 \\
\hline Eucatex & - & 4 \\
\hline Bann Química & & \\
\hline
\end{tabular}

Indagados sobre a origem dos maus odores, os entrevistados espontaneamente forneceram as informações constantes na Tabela 9, onde destacaram-se as indústrias em geral, especificamente a Replan, o rio Atibaia, a Brahma e a Rhodia. 


\section{Conclusão}

Pesquisas de opinião, ainda que sejam um modo indireto e nem sempre 100\% confiáveis, permitem vislumbrar grandes problemas ambientais, os quais necessitam observação mais sistemática. Os dados apresentados, através de entrevistas realizadas em 1994/1995 e posteriormente em 2002, permitiram que se fizesse uma comparação temporal entre a ocorrência de poluição do ar e a percepção dos moradores de Paulínia quanto a esse fator. Notou-se que o grau de intensidade dos problemas não foi modificado, o que requer atitudes mais efetivas por parte do poder público.

\section{Notas}

* O monitoramento da qualidade do ar de Paulínia foi realizado com o uso de uma estação volante da rede telemétrica da CETESB. Para cada poluente avaliado, foi utilizado um equipamento automático específico, que coleta e analisa a amostra em questão. Os dados gerados pelos monitores foram armazenados em um microcomputador da própria estação, sendo após, transferidos para a estação central de processamento da rede telemétrica, onde foram processados e analisados.

1 Os autores agradecem à Capes e a CETESB/SP.

2 CETESB - Avaliação da Qualidade do Ar. Paulínia Jan/92 a Mar/92. D.N.P.A. - Depto. Qualidade Ambiental e Padrões. NPQI/NPQT. São Paulo, 1992.

3 CETESB - Avaliação da Qualidade do Ar em Paulínia (SP) - Junho a Agosto/1998. Divisão da Qualidade do Ar. São Paulo, 1999.

4 CETESB - Pesquisa de Opinião Ambiental no Município de Paulínia, 1994/1995.

5 SMA, Governo do Estado de São Paulo. Bacia do Rio Piracicaba - Estabelecimento de Metas Ambientais e reenquadramento dos corpos d’água. São Paulo, 1994. 81p.

\section{Referências}

GUTJAHR, M. R. A poluição do ar em Paulínia (SP): uma análise histórico-geográfica do clima. Tese de doutoramento. São Paulo. Departamento de Geografia, FFLCH-USP, 2002.

Recebido para publicação nos Anais do VI Congresso Brasileiro de Geógrafos no mês abril de 2004 